\title{
The Fault Causes of Overhead Lines in Distribution Network
}

\author{
Li Wang \\ State Grid Nanchong Power Supply Information \& Telecommunication Co. Ltd., Sichuan, 637000, China
}

\begin{abstract}
The paper introduces the typical fault causes in distribution system, especially the fault in overhead line. The data in the paper are from the surveys by different agencies all around the world. It is noted that the statistics are different with each other for many reasons, and some of them are old which was finished in 1980s. The fault causes in different areas (Nordic, North American and China) are introduced separately. Some typical fault causes (trees, animals, lightning, and vehicles) are subdivided and analyzed in detail. Some waveforms of different faults are shown in the paper too. At last, the most frequent fault causes which should be focused on are proposed by the paper.
\end{abstract}

\section{Introduction}

There are lots of fault causes could lead to power outage, including the equipment failure, lightning, trees and so on. Some utilities and agencies have surveyed the power outage causes in power system 1-4. It is reported that most of the power outages are caused by the fault in distribution system (about $80 \%$ based on the statistics in Norway5) for the large number of distribution lines distributed in the complex environments. This paper focuses on the investigation about fault causes in distribution system, especially the fault on overhead line and underground cable.

The fault is inevitable in distribution system for many uncontrollable factors, such as animals, weather related factors. The different kinds of fault causes have the similar fault features. The fault causes can be identified by the fault feature analysis which is useful for the faultfinding and fault-clearing when a fault happened. It is noted that some statistics in the paper is about transmission line fault causes, although the fault causes are similar, the percentages of the fault causes are different.

A large EPRI study was done to characterize distribution faults in the 1980 s at 13 utilities monitoring 50 feeders67. The fault causes are classified into 11 types: lightning, tree contact, equipment failure, animal, wind, dig-in, vehicle accident, ice/snow, vandalism, construction activity and other. In ref 1 and 2 , the power outage was grouped into 8 possible causes by EATON, including animal, faulty equipment/human error, planned, unknown, vehicle accident, weather/trees, theft/vandalism, over demand. It is note that not all the power outage is caused by fault. ENTSOE(European network of transmission system operators for electricity) classified the fault causes into 7 types in 3 , including lightning, other environmental cause, external influence, operation and maintenance, technical equipment, other and unknown. Alberta municipal affairs classified the damage on overhead line contacts in detail in 4 . The reported faults in 4 are caused by mankind, including intentional and unintentional. The underground utility system fault causes are classified into excavating equipment, vehicles hitting transformers, pedestals, etc. There are 6 types of fault causes in urban distribution system classified by State Grid in China, including external factors, natural factors, improper maintenance and operation, improper installation, equipment failure and customer cause, as shown in Fig.1. The mentioned fault cause types can be subdivided into some specific fault causes.

\section{Influence factors}

The types of fault causes are similar, but the proportions are different in different countries, under different weather conditions and so on. Ref10 analyzed the weather related factors. Ref 11 introduced the influence of conductor type and environment. Ref 12 compared the fault causes data in different area of Duke power distribution systems.

All in all, the influence factors can be summarized as follows:

(1) The different grounding system: the system can be divided into effectively grounded system(including solidly grounded and low resistance grounded system which are used in north America) and non-effectively grounded system(including ungrounded, high resistance grounded and resonant grounded which are mainly utilized in Nordic and China)

(2) The conductor type: the fault causes in overhead line, covered conductor overhead line, underground cable and air cable are always different. The overhead line and the underground cable are the most commonly used in distribution system which are considered in this paper.

(3) The geographical environment: the fault causes in plain and forest are different; the tree caused fault and animal caused fault in forest area would be more. 
(4) The weather/climate/season: the lightning fault is more in summer and the high wind would cause more tree related fault.

(5) Some other factors, such as the development of the area. There would be more construction caused faults in developing countries, such as China.

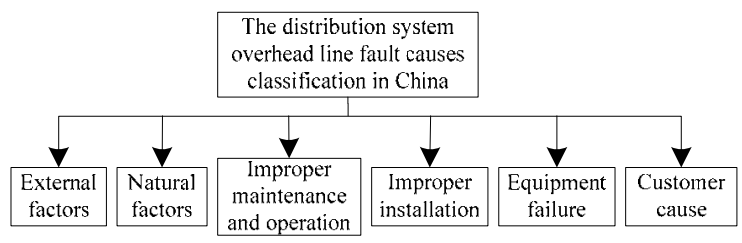

(a) The distribution system fault causes classification

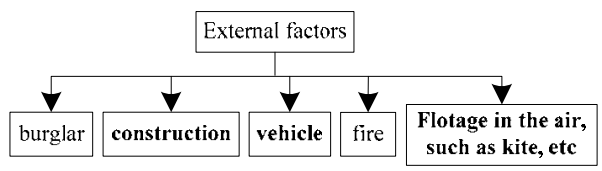

(b) The subdivided of external factors

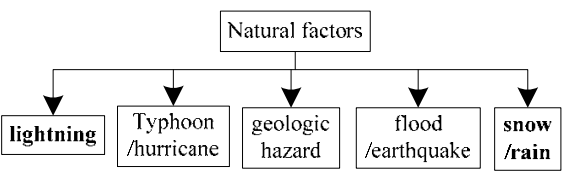

(c) The subdivided of natural factors

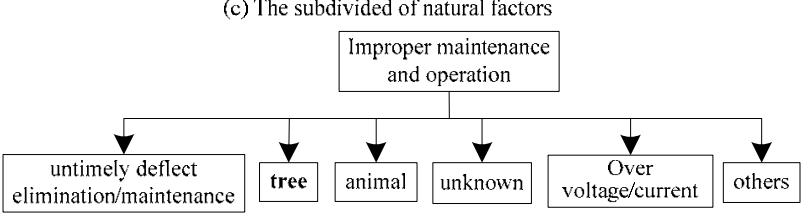

(d) The subdivided of Improper maintenance and operation

Note: the bolted are the high frequent fault causes

Figure 1. Fault causes classification in China.

\section{Overhead line fault causes}

\subsection{The overhead line faults in North American}

\subsubsection{The statistics from EPRI}

A large survey done by EPRI was finished in the 1980s at 13 utilities monitoring 50 feeders(in north America) 7. The fault causes reported in the EPRI is shown in Figure $2.1^{67}$. Approximately $40 \%$ of the faults occurred during periods of "adverse" weather, which include rain, snow, and ice. The top three fault causes are lightning, tree contact and equipment failure.

\subsubsection{The statistics from Duke power system}

Because of the factors mentioned last section, the statistics of the fault causes are different with each other. The fault causes and its distribution in Duke power system(north America, data between 1987 and 1990) are: trees $(19 \%)$, animals(18\%), equipment failure(14\%), lightning( $9 \%)$, public accidents(10\%), other(13\%) and unknown(17\%).

\subsection{The overhead line faults in Nordic}

The fault in distribution system is different with the fault in transmission system. Some countries have analyzed the fault causes in distribution system, such as Norway5 and Finland13. The division of the fault causes in Finland was as follows: snow burden $35 \%$, fallen trees $27 \%$, boughs on pole transformers $9 \%$, diggers $6 \%$, lightning impulses $6 \%$. The rest of the faults $(17 \%)$ were probably caused by animals such as birds and squirrels, because the faults were cleared by an additional delayed reclosing. The causes of the disturbances cleared by auto-reclosing remained unknown. However, about one third of these events occurred during thunderstorms or windy weather ${ }^{14}$.

\subsection{The overhead line faults in China}

The distribution system fault causes in China contain external factors, natural factors and some of the improper maintenance factors. The external factors caused fault is high all over the year, especially the construction, vehicle and flotage caused. It can be found that fault causes are affected by the seasons apparently. The fault number in summer is much more than other seasons for the terrible weather, such as lightning and high wind.

\section{Typical Fault Analysis}

In this section, some typical faults will be introduced in detail and some of the waveforms would be attached. The tree, animal and lightning caused faults have been analyzed by many research groups for the faults have the similar features. The partial discharge $\mathrm{e}^{1516}$ and the cable joint faults ${ }^{8}$ identification in cable are also introduced in many references. But the man-made faults in overhead line (vehicle and construction related) and the external faults (construction related) in underground cable are hard to be identified.

\subsection{Tree caused faults(overhead line)}

Trees can cause faults in several ways: growth into conductors, failing trees or branches bridging gaps or pushing conductors together, and failing trees or branches causing mechanical damage 17. Results of utility surveys show that growth is normally less than $15 \%$ of permanent interruptions. Dead trees or branches account for about 30 to $40 \%$ of tree faults, and trees with significant defects account for another significant portion. Faults caused by trees generally occur from a handful of conditions: 1) Falling trees or major limbs knock down poles or break pole hardware; 2) Tree branches blown by the wind push conductors together; 3) A branch falls across the wires and forms a bridge from conductor to conductor; 4) Natural tree growth causes a bridge across conductors.

The results from several utilities outlined below show that broken tree branches or falling trees account for the majority of interruptions. Growth only accounts for a small percentage of interruptions. Simpson reported on a survey of tree-caused faults at Eastern Utilities Associates (a small utility in Massachusetts that is now a part of National Grid). The main results were that treecaused outages broke down as follows: $63 \%$ from broken 
branches, $11 \%$ from falling trees, $2 \%$ from tree growth. Document surveyed by BC Hydro of their tree-related interruptions that were as follows: $70 \%$ from tree failure, $18 \%$ from branch failure, $12 \%$ from growth.

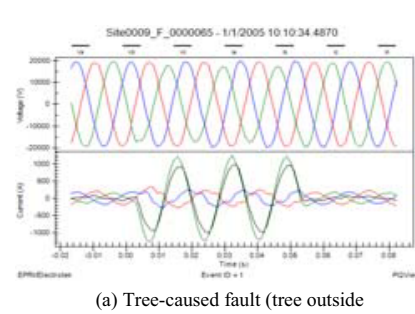
(a) Tree-caused fault (tree outside
right of way, fall/lean on primary)

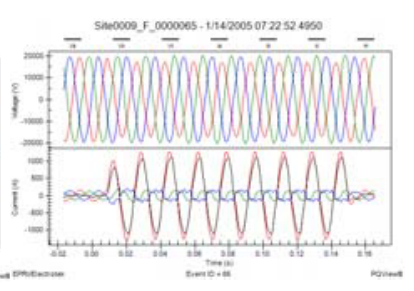

(b) Tree-caused fault (tree/limb growth)
Figure 2. Tree-caused fault waveforms (ref. 20)

\subsection{Animal caused faults(overhead line)}

\subsubsection{Statistics of the animal-caused faults}

There are many types of animals could cause fault in power system, including tree squirrel, birds, snake and so on. Also the animal-caused faults may occur on overhead distribution lines, underground distribution circuits, substations, and transmission lines. The EPRI work group has surveyed some utilities in North American about the animal-caused fault between 1993 and 1997. The statistics shows that thirty-five of 84 utilities(42\%) estimate overhead distribution lines are associated with $79 \%$ of historic animal-caused outage events. In this paper, only the overhead line related animal-caused faults would be introduced.

Eighty utilities repot outage frequency is apportioned between mammals (64\%) and birds (36\%). The most problematic mammals are tree squirrels and raccoons, thirty-eight utilities indicate tree squirrels are responsible for the greatest frequency of all animal-caused overhead outages; raccoons are listed by another five utilities. Birds are responsible for the second greatest frequency of all distribution overhead outages. Twenty utilities(25\%) report most bird outage are caused by unknown bird species.

In fact, some equipments are more susceptible to animal-caused damage and outages. Utilities were provided a list of common distribution items and asked to rank their top five animal-caused outage duration and frequency problem items: transformers, cutouts, surge arresters, jump wire contacts, phase to neutral contacts.

Table 1. Animals associated with the top six distribution overhead items associated with animal-caused outages(ref. 18 )

\begin{tabular}{|c|c|}
\hline $\begin{array}{l}\text { Items Associated } \\
\text { with Animal-. } \\
\text { Caused Outages }\end{array}$ & Most Common Animals and Number of Reporting Utilities \\
\hline Power transformers & $\begin{array}{l}\text { Mammals - 46: Tree Squirrels (21), Raccoons (14), Ground Squirrels (5), Other (6) } \\
\text { Birds - 22: Unknown (8), Hawks (3), Blackbirds (2), Other (9) }\end{array}$ \\
\hline Cutouts & $\begin{array}{l}\text { Mammals - 18: Tree Squirrels (10), Raccoons (3), Ground Squirrels (2), Cats (2), Other (1) } \\
\text { Birds - 16: Unknown (4), Blackbirds (4), Hawks (3), Other (5) }\end{array}$ \\
\hline Surge arresters & $\begin{array}{l}\text { Nhammals - 24: Tree Squirrels (14), Raccoons (5), Ground Squirrels (2), Cats (2), Other (1) } \\
\text { Birds - 15: Unknown (8), Blackbirds (2), Owls (2), Other (3) }\end{array}$ \\
\hline $\begin{array}{l}\text { Jumper wires } \\
\text { contacts }\end{array}$ & $\begin{array}{l}\text { Mammals - 18: Tree Squirrels (7), Raccoons (4), Cats (3), Other (4) } \\
\text { Birds - 14: Unknown (5), Blackbirds (3), Hawks (3), Other (3) }\end{array}$ \\
\hline $\begin{array}{l}\text { Phase-to-neutral } \\
\text { contacts }\end{array}$ & $\begin{array}{l}\text { Mammals - 18: Tree Squirrels (6), Ground Squirrels (5), Cats (2), Raccoons (2), Other (3) } \\
\text { Birds - 19: Unknown (7), Eagles (2), Hawks (2), Owls (2), Other (6) }\end{array}$ \\
\hline Reclosers & $\begin{array}{l}\text { Mammals - 29: Tree Squirrels (12), Raccoons (8), Ground Squirrels (4), Other (5) } \\
\text { Birds - 15: Unknown (7), Hawks (3), Blackbirds (3), Other (2) }\end{array}$ \\
\hline
\end{tabular}

\subsubsection{The waveforms of the animal-caused faults20}

The waveforms of animal-caused faults are from DOE/EPRI National database20. Some of the typical fault are shown as follows, but the fault process and fault position are unknown. The different types of animalcaused fault are introduced in 19.
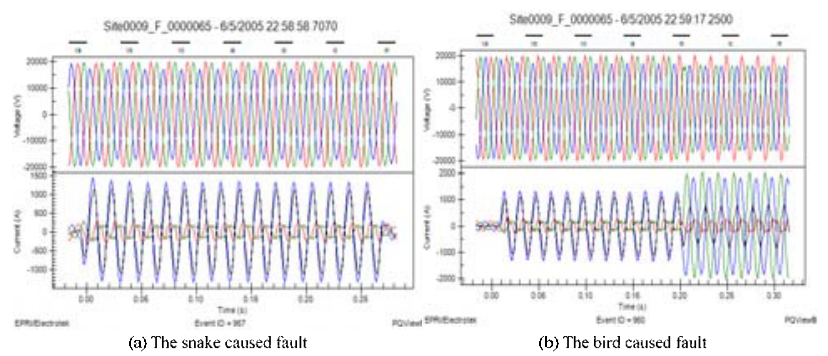

Figure 3. Two animal-caused fault cases(ref. 20)

\subsection{Lightning caused faults(overhead line)}

In the majority of cases, lightning causes temporary faults on distribution circuits; the lightning arcs externally across insulation, but neither the lightning nor the fault arc permanently damages any equipment. Normally, less than $20 \%$ of lightning strikes cause permanent damage. Lightning causes most damage by directly striking an overhead phase wire and injecting an enormous current surge that creates a very large voltage. The voltage impulse easily breaks down most distribution-class insulation unless it is protected with a surge arrester. Almost all direct lightning strokes cause flashovers. In addition, the lightning current may start a pole fire or burn through conductors. Also, nearby lightning strokes that don't hit the line may couple damaging voltages to the line. These induced voltages may fail equipment or cause flashovers.
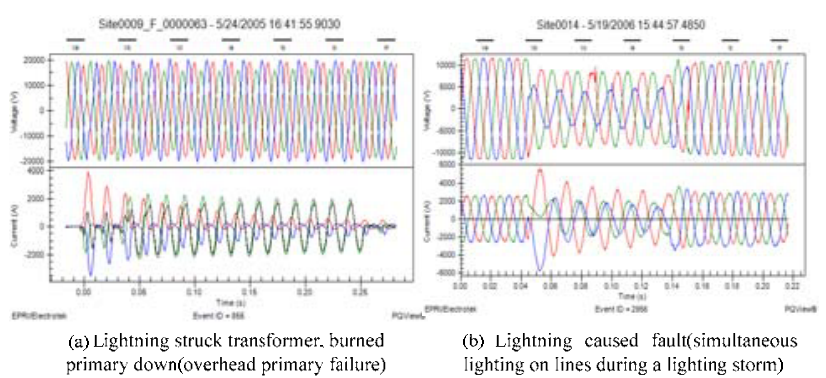

Figure 4. Lightning caused fault waveforms (ref. 20) 


\subsection{Vehicle caused faults (overhead line)}

The feature of this type fault is irregular for the stochastic fault process. The faults always cause pole damage. Some of the fault waveforms are shown in Fig. 5.

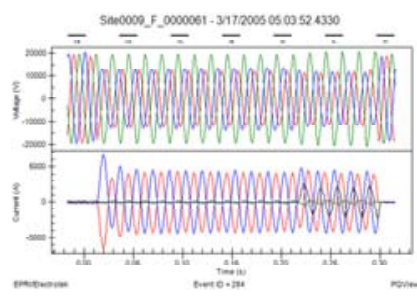

(a) Vehicle caused fault(car hit pole)

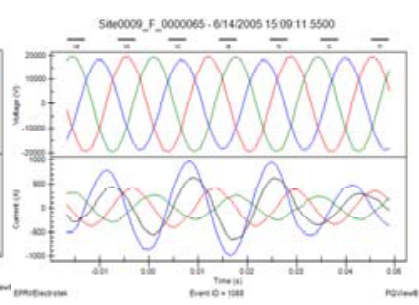

(b) Vehicle caused fault(car hit guy wire)
Figure 5. Vehicle caused fault waveforms (ref. 20)

\subsection{The relationship between fault type and fault causes}

The different fault type happened in distribution and the relationship with fault causes have been surveyed by some references7917. It is reported that almost $80 \%$ of the faults measured involved only one phase either in contact or with ground. As another data point, measurements on $34.5 \mathrm{kV}$ feeders found that $75 \%$ of faults involved ground (also 54\% were phase to ground, and $15 \%$ were phase to phase). Most faults are single phase because most of the overall length of distribution lines is single phase (in North American), so any fault on single-phase sections would only involve one phase. Equipment faults and animal faults tend to cause line-toground faults. Trees can also cause line-to-ground faults on three-phase structures, but line-to-line faults are more common. Lightning faults tend to be two or three phases to ground on three-phase structures7. The relationship between fault causes and fault type is also surveyed by 9 , which is shown in Table 3.

Table 2. Number of phases involved in each fault measured in the EPRI fault study (ref. 7)

\begin{tabular}{|c|c|}
\hline Fault & Percentage \\
\hline One phase to neutral & $63 \%$ \\
\hline Phase to phase & $11 \%$ \\
\hline Two phases to neutral & $2 \%$ \\
\hline Three phase & $2 \%$ \\
\hline One phase on the ground & $15 \%$ \\
\hline Two phases one the ground & $2 \%$ \\
\hline Three phases on the ground & $1 \%$ \\
\hline Other & $4 \%$ \\
\hline
\end{tabular}

Table 3. The relationship between some fault causes and fault types (ref. 9)

\begin{tabular}{|c|c|c|c|}
\hline Event & $\begin{array}{c}\text { Single phase } \\
\text { faults }\end{array}$ & $\begin{array}{c}\text { Multiphase } \\
\text { faults }\end{array}$ & $\begin{array}{c}\text { Total } \\
\text { cases }\end{array}$ \\
\hline $\begin{array}{c}\text { Animal } \\
\text { contact }\end{array}$ & $53(86.88 \%)$ & $8(13.12 \%)$ & 61 \\
\hline Tree contact & $66(73.33 \%)$ & $24(26.67 \%)$ & 90 \\
\hline $\begin{array}{c}\text { Lightning } \\
\text { induced }\end{array}$ & $8(42.1 \%)$ & $11(57.9 \%)$ & 19 \\
\hline
\end{tabular}

The fault cause is also related to the weather. For one northeastern US utility, "Tree Contact" leads all other outage categories during stormy weather; and it especially stands out during wind and ice/snow. This highlights the fact that tree caused faults increase rapidly during storms.

Faults are either temporary or permanent. A permanent fault is one where permanent damage is done to the system. This includes insulator failures, broken wires, or failed equipment such as transformers or capacitors. Virtually all faults on underground equipment are permanent. Most equipment fails to a short circuit. Permanent faults on distribution circuits usually cause sustained interruptions for some customers. A temporary fault does not permanently damage any system equipment - if the circuit is interrupted and then reclosed after a delay, the system operates normally. Temporary (non-damage) faults make up $50-90 \%$ of faults on overhead distribution systems. Some causes of faults are more likely than others to be permanent. The causes of temporary faults include lightning, conductors slapping together in the wind, animals that cause faults and fall off, and insulator flashovers caused by pollution7.

\section{Summary}

The fault causes in distribution system have been investigated in this paper. The fault in overhead line and underground are introduced separately. Some common faults(tree, lightning, animals and so on) are introduced in detail, and waveforms are shown in the paper. Some features of the different fault causes can be conclude as follows:

- The overhead line fault is high related to the weather condition: tree caused fault is more frequent under high wind condition, lightning fault is easy to identify by the weather. The information about weather is useful for the fault feature identify.

- The animal caused fault is frequent in north America which is always happen in spring, and fault resistance and fault type are regular.

- The man-made fault(construction and vehicle) in overhead line is hard to identify for its stochastic fault condition.

- The equipment failure related fault (including the flash over in overhead line and partial discharge in the underground cable) always caused by the insulation decaying, so there would be some disturbances before the fault which can be used as criterion.

- The external caused fault(construction) in underground cable is mainly because excavator digging which would damage the cable, the fault features are irregular, so it is hard to identify.

The fault causes have been introduced in this paper, but the fault process and some more details about the fault haven't been presented which would be investigated in the future. The fault process is dynamic and fickle, so 
the dynamic of the model should be considered for the accurate fault analysis and identification.

\section{References}

1. Power outage annual report. Blackout Tracker Canada annual repot 2013 (Get from: pqlit.eaton.com/11_download_bylitcode.asp?doc_id= 24005)

2. Power outage annual report. Blackout Tracker United States annual repot 2013 (Get from: pqlit.eaton.com/11_download_bylitcode.asp?doc_id= 24003)

3. European Network of Transmission System Operators for Electricity. Nordic grid disturbance statistics 2012. (Get from: http://www.fingrid.fi/fi/voimajarjestelma/voimajarje stelmaliitteet/S\%C3\%A4hk\%C3\%B6n\%20toimitus varmuus/Pohjoismainen_hairiotilasto_2012.pdf)

4. Alberta Municipal Affairs. Statistics electrical incidents in Alberta(January 1 to December 31, 2013)(Get

from:http://www.municipalaffairs.alberta.ca/cp_elec trical_forms_and_reports.cfm)

5. Gerd H.Kjolle. What do fault statistics tell us regarding causes resulting in power outages?(Get from:

https://www.sintef.no/project/Vulnerability\%20and $\% 20$ security/Publications/Presentations/Workshop\% 2020110927_fault\%20statistics.pdf)

6. Burke, James J., and D. J. Lawre. "Characteristics of fault currents on distribution systems." Power Apparatus and Systems, IEEE Transactions on 1 (1984): 1-6.

7. Power Quality Implications of Distribution Construction, EPRI, Palo Alto, CA: 2004. 1002188

8. Mehairjan, R. P. Y. I. Application of Statistical Life Data Analysis for cable joints in MV Distribution Networks-An Asset Management Approach. Diss. MSc Thesis Report, Delft University of Technology: Electrical Engineering, 2010.

9. Kulkarni, Saurabh, et al. "Waveform characterization of animal contact, tree contact, and lightning induced faults." Power and Energy Society General Meeting, 2010 IEEE. IEEE, 2010.

10. Campbell, Richard J. "Weather-related power outages and electric system resiliency." Congressional Research Service, Library of Congress, 2012.

11. Lehtonen, Matti. "Fault rates of different types of medium voltage power lines in different environments." Electric Power Quality and Supply Reliability Conference (PQ), 2010. IEEE, 2010.

12. Chow, Mo-Yuen, and Leroy S. Taylor. "A novel approach for distribution fault analysis." Power Delivery, IEEE Transactions on 8.4 (1993): 18821889.

13. Kimmo Kivikko. Assessment of electricity distribution reliability-interruption statistics, reliability worth, and applications in network planning and distribution business regulation.
Doctor thesis, 2010, Tampere university of technology

14. Hanninen, S., M. Lehtonen, and T. Hakola. "Earth faults and related disturbances in distribution networks." Power Engineering Society Summer Meeting, 2001. Vol. 2. IEEE, 2001.

15. Zhang, Xiang, et al. "Estimation of the lifetime of the electrical components in distribution networks." Power Delivery, IEEE Transactions on 22.1 (2007): 515-522.

16. Densley, John. "Ageing mechanisms and diagnostics for power cables-an overview." Electrical Insulation Magazine, IEEE 17.1 (2001): 14-22.

17. Power Quality Implications of Transmission and Distribution Construction: Tree Faults and Equipment Issues, EPRI, Palo Alto, CA: 2005. 1008506.

18. Mitigation of animal-caused outages for distribution lines and substations, EPRI, Palo Alto, CA: 1999.Report TE-114915

19. Distribution Wildlife and Pest Control, EPRI, Palo Alto, CA: 2001. 1001883

20. DOE/EPRI National Database Repository of power system events (get from: http://expertmonitoring.com/doelibrary/) 